\title{
INFLUENCE OF AUSTENITIZING AND TEMPERING TEMPERATURE ON MICROSTRUCTURE, SUBSTRUCTURE AND MECHANICAL PROPERTIES OF CREEP RESISTANT 9CrNb STEEL
}

\author{
Pavel BEKEČ ${ }^{1 *}$, L'udovít PARILÁK ${ }^{1,2}$, Pavol BERAXA ${ }^{1,2}$, Martin FUJDA $^{3}$, Miloš MATVIJA ${ }^{3}$ \\ 1ŽP Research and Development Centre, Ltd., Podbrezova, Slovak Republic, EU \\ *bekec@zelpo.sk,parilak@zelpo.sk, beraxa.pavol@zelpo.sk \\ ${ }^{2}$ Faculty of Manufacturing Technologies with a Seat in Prešov, Prešov, Slovak Republic, EU \\ ${ }^{3}$ Faculty of Materials, Metallurgy and Recycling of the Technical University of Košice, Slovak Republic, EU, \\ martin.fuida@tuke.sk,.milos.matvija@tuke.sk
}

\begin{abstract}
https://doi.org/10.37904/metal.2019.705
This paper deals with influence of austenitizing and tempering temperature on microstructure, substructure and mechanical properties of creep resistant $9 \mathrm{CrNB}$ steel. Austenitizing temperature of $1050^{\circ} \mathrm{C}$ was used with holding time of $15 \mathrm{~min}$ (state N1) and $45 \mathrm{~min}$ (state N3). Subsequently, the samples in these conditions were tempered at $790{ }^{\circ} \mathrm{C} / 60 \mathrm{~min}$ (state $\mathrm{S} 1$ and S3). Microstructure after austenitization is formed by lath martensite and low bainite. The microstructure after tempering was formed by tempered martensite and lower bainite, with darker and lighter areas. This is due to the non-homogeneous distribution of precipitates. It can also be seen, that fine particles of precipitates were found at the martensite and low bainite lattice interfaces. It is likely to be a carbide particles, whereby excluded this particles occurred during the tempering on the original grain boundaries of austenite. The substructure was analysed in the following austenitizing conditions: $1050{ }^{\circ} \mathrm{C} / 15$ min and $1050^{\circ} \mathrm{C} / 45 \mathrm{~min}$ and their subsequent tempering at $790{ }^{\circ} \mathrm{C} / 60 \mathrm{~min}$. The precipitates were identified by selective electron diffraction analysis. The mechanical properties were evaluated after austenitization and tempering conditions.
\end{abstract}

Keywords: Creep resistant steel, martensitic microstructure, tempering temperature, $9 \mathrm{Cr}$ steel, boron, grain boundary

\section{INTRODUCTION}

There is a lot of pressure on the use of alternative sources in the energy industry, worldwide. This is due to increased $\mathrm{CO}_{2}$ emissions and global warming. In spite of these facts, thermal power plants are burning fossil fuels resp. other fuels continue to be a major electricity producer. The development of creep resistant alloy grades is related to the constant increase in temperatures and pressures at which energy equipment operates. Increasing the temperatures and pressures increases the efficiency of the energy equipment and reduces the production of harmful emissions such as $\mathrm{CO}_{2}, \mathrm{SO}_{2}, \mathrm{NO}_{x} .9 \% \mathrm{Cr}$ steel (P91, P92) is used for the construction of critical components of these power plants due to their high corrosion resistance. They are designed for supercritical application parameters, temperature using $600-620^{\circ} \mathrm{C}$ and steam pressure $30 \mathrm{MPa}$. Nowadays new grades of high strength martensitic steels are currently being developed with a use temperature of up to $650{ }^{\circ} \mathrm{C}$ and a steam pressure of $35 \mathrm{MPa}$. In these steels is achieved increasing of the creep resistance substituting molybdenum by tungsten and addition of cobalt, nitrogen, niobium and boron. One of these steels is the newly developed $9 \mathrm{CrNB}$ steel [1-8]. The required mechanical properties and creep resistance of these steels can be achieved only by applying a suitable mode of their heat treatment. The main aim was to describe microstructure, substructure and mechanical properties of $9 \mathrm{CrNB}$ steel after austenitization at temperature $1050^{\circ} \mathrm{C}$ (holding time 15 and $45 \mathrm{~min}$.) and subsequent tempering at $790{ }^{\circ} \mathrm{C}$ (holding time $60 \mathrm{~min}$.).

\section{MATERIAL AND EXPERIMENTAL METHODS}

The 9 CrNB steel was used as an experimental material, from which seamless hot-rolled tubes were produced with dimensions of $88.9 \mathrm{~mm} \times 12.5 \mathrm{~mm}$. The chemical composition of 9CrNB steel is shown in Table 1. The 
tubes were austenitized at the temperatures of $1050{ }^{\circ} \mathrm{C}$ with holding time $15 \mathrm{~min}$ (N1) and a $45 \mathrm{~min}$ (N3) and tempered at $790^{\circ} \mathrm{C} / 60 \mathrm{~min}(\mathrm{~S} 1$ and S3).

Table 1 Chemical composition of 9CrNB steel

\begin{tabular}{|c|c|c|c|c|c|c|c|c|c|c|c|c|}
\hline Elements & C & Mn & Si & P & S & Cr & Ni & Mo & W & Co & B & N \\
\hline Min (t. \%) & 0.06 & 0.40 & 0.20 & - & - & 8.00 & - & - & 2.50 & 2.80 & 0.010 & 0.005 \\
\hline Max (wt. \%) & 0.10 & 0.50 & 0.35 & 0.020 & 0.008 & 9.00 & 0.15 & 0.10 & 3.00 & 3.20 & 0.015 & 0.015 \\
\hline
\end{tabular}

The samples were prepared by standard metallographic procedures (grinding, polishing, and etching). Microstructural analysis was carried out using an Olympus GX51 light optical microscope. The state of precipitation of carbide and other phases in steel was analysed by the JEOL JEM 2000FX Transmission Electron Microscope (TEM) by the method of carbon extraction replicas. They were removed from the metallographically prepared areas after being separated in the Villela etchant. The role of the analysis was to characterize the morphology of the transformed substructure, morphology, size and distribution of the precipitates. The main aim was to study the influence of the conditions of different temperature and holding time on microstructure, substructure and mechanical properties.

\section{RESULTS}

\subsection{State $\mathrm{N} 1\left(1050^{\circ} \mathrm{C} / 15 \mathrm{~min}\right)$ and state $\mathrm{N} 3\left(1050^{\circ} \mathrm{C} / 45 \mathrm{~min}\right)$}

Microstructure consists of martensite and low bainite (Figure 1). Microstructure is homogeneous from austenitic grain size point of view. The particles observed in the microstructure, precipitated also at the original austenite grain boundaries (Figure 2).

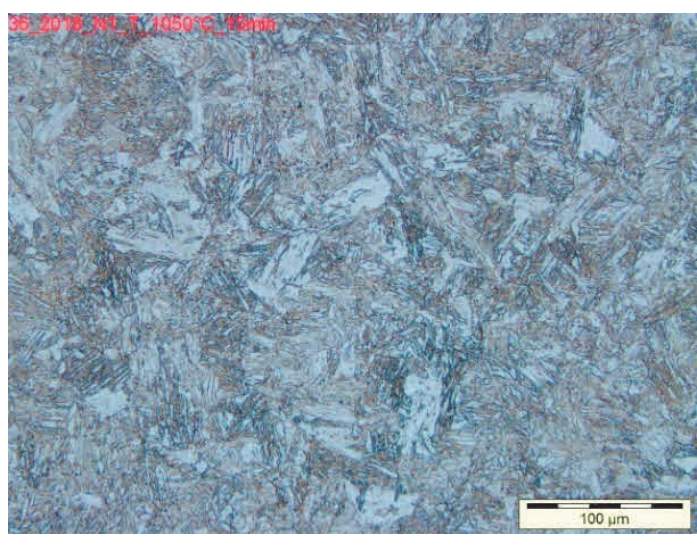

Figure 1 microstructure after austenitization state $\mathrm{N} 1 \_1050{ }^{\circ} \mathrm{C} / 15 \mathrm{~min}$

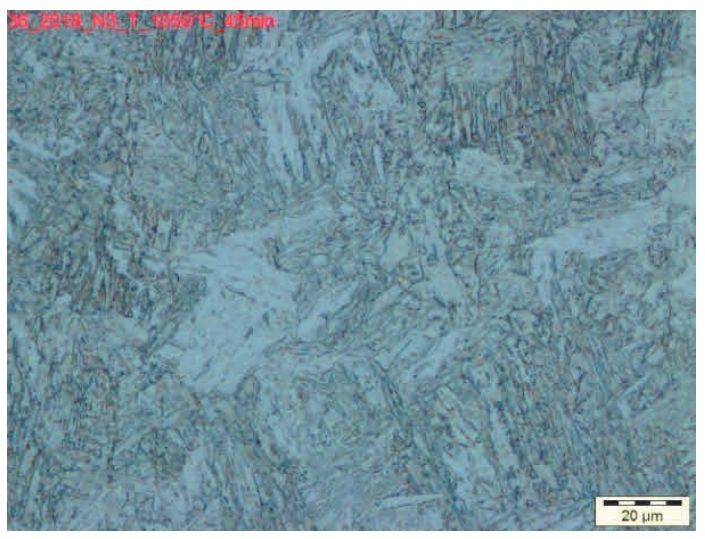

Figure 2 microstructure after austenitization state N3_1050 ${ }^{\circ} \mathrm{C} / 45 \mathrm{~min}$

The two states (N1 and N3) were evaluated by TEM (carbon replicas method). And it was found, that substructure was formed of martensite and bainite laths, which were created in a relatively coarse original austenitic grain. In substructure oval particles with an average size of $200 \mathrm{~nm}$ and also irregular particles with uneven distribution with an average size of $800 \mathrm{~nm}$ were present in some areas. A large extent of irregular coarser particles was bound to the original austenite grain boundaries (Figure 3). They were also within the martensite and bainite laths as well as smaller sized particles. The particles have a rod-shaped character inside the martensite and bainite and have different orientation in different regions of the substructure and reached an average length of $130 \mathrm{~nm}$. Inside the martensite and bainite and their interfaces are also visible smaller globular and oval particles with an average size $50 \mathrm{~nm}$ (Figure 4). 


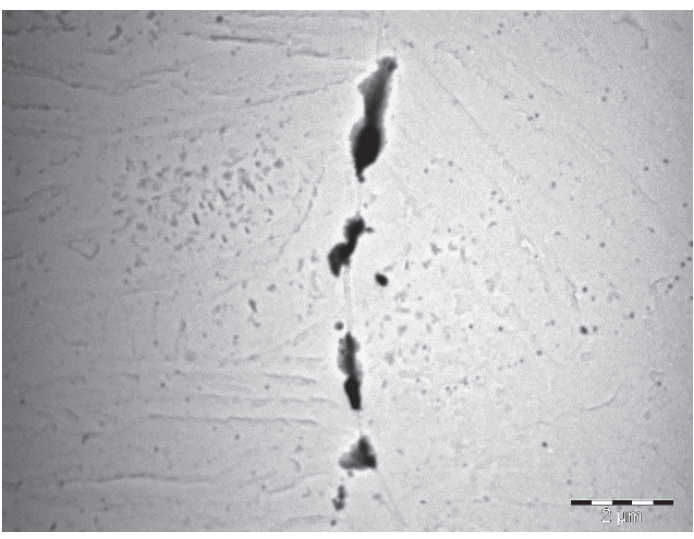

Figure 3 substructure and distribution of the precipitates, N3_1050 ${ }^{\circ} \mathrm{C} / 45$ min

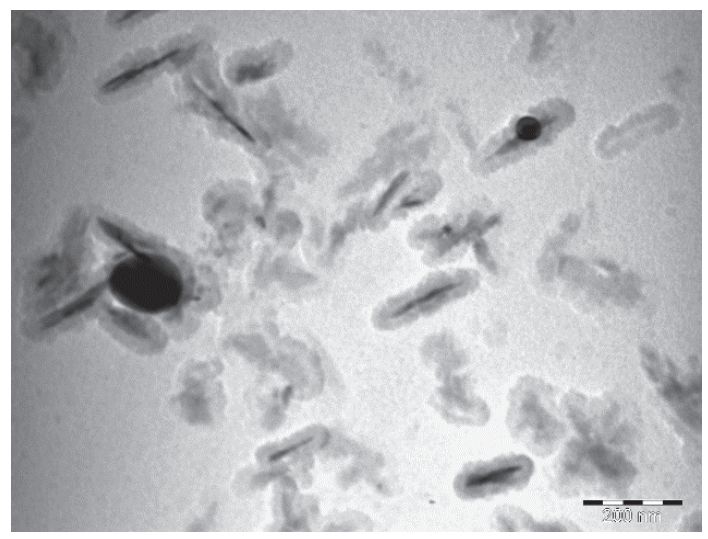

Figure 4 detail of rod-shaped and oval particles inside bainite, $\mathrm{N} 1 \_1050{ }^{\circ} \mathrm{C} / 15 \mathrm{~min}$

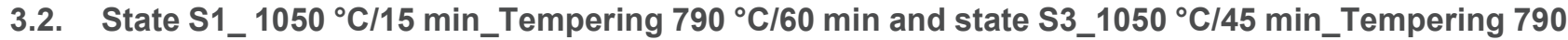 ${ }^{\circ} \mathrm{C} / 60 \mathrm{~min}$}

Microstructure consists of tempered martensite and tempered low bainite. They are visible as darker and lighter areas (Figure 5). This is due to the inhomogeneous distribution of the precipitates. In the light regions of the microstructure, the proportion of precipitates was smaller, in darker areas was bigger. The fine particles of precipitates were found at boundaries lath of tempered martensite and lower bainite. These precipitates are most probably carbides that precipitated also at the original austenite grain boundaries during tempering (Figure 6).

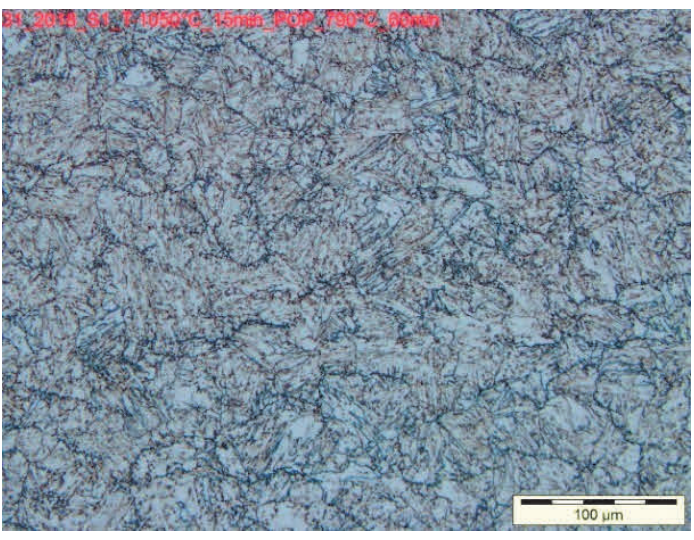

Figure 5 microstructure after normalizing at $1050{ }^{\circ} \mathrm{C} / 15 \mathrm{~min}$ and tempering $790{ }^{\circ} \mathrm{C} / 60 \mathrm{~min}$, (state S1)

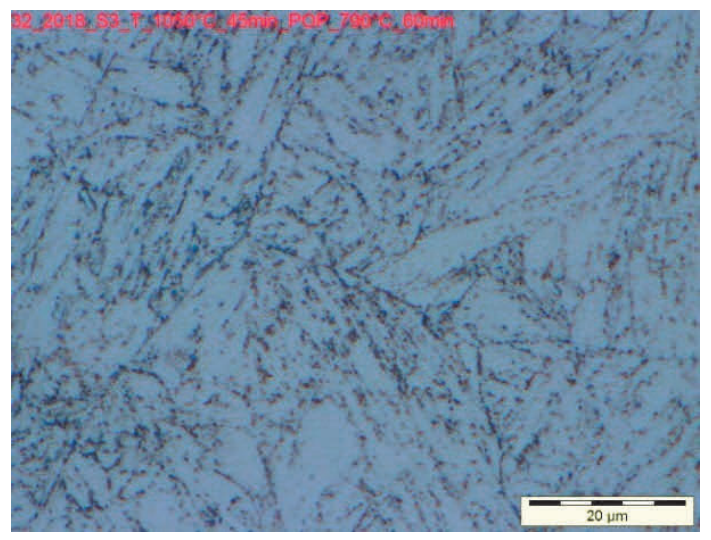

Figure 6, microstructure after normalizing at $1050{ }^{\circ} \mathrm{C} / 45 \mathrm{~min}$ and tempering $790{ }^{\circ} \mathrm{C} / 60 \mathrm{~min}$,

(state S3)

The substructure was heterogeneous, formed by particles of different morphology and size, whose distribution was uneven. The particles were precipitated at the original austenitic grain boundaries, at the interface of the tempered martensite and tempered bainite laths and inside the tempered bainite (Figure 7, 8). Globular to oval particles reached an average size $60 \mathrm{~nm}$. These particles are identified as $\mathrm{Nb}, \mathrm{V}, \mathrm{C}$ or $\mathrm{Nb}, \mathrm{V}, \mathrm{B}, \mathrm{C}$, based on results of EDX analysis. Particles on base $\mathrm{Nb}, \mathrm{V}$ and $\mathrm{C}$ were identified by selection electron diffraction analysis as niobium carbides with possible vanadium atom substitusion in the crystallographic cubic $\mathrm{NbC}$ centered lattice (state S1 and S3). Particles on base Nb, V, B a C were identified as niobium carbides alloyed with boron with possible vanadium atom substitution in the crystallographic cubic NbC centered (state S1) and niobium boride with possible substitution of vanadium atoms in the crystallographic orthorhombic lattice of $\mathrm{NbB}$ phase (state S3). Larger oval to rod-shaped particles reached a length of $200 \mathrm{~nm}$ and a width of $50 \mathrm{~nm}$. EDX 
analysis showed that they were based on $\mathrm{Cr}, \mathrm{Fe}, \mathrm{W}$ and $\mathrm{C}$. The particles were identified by selection electron diffraction analysis as complex $\mathrm{M}_{23} \mathrm{C}_{6}$ type carbides crystallizing in a crystallographic cubic surface centered lattice with possible substitution of chromium, iron and tungsten atoms. EDX analysis showed, that coarse oval to irregular particles present at the original austenitic grain boundaries of size $350 \mathrm{~nm}$ (state S1) up to $700 \mathrm{~nm}$ (state S3) were based on $\mathrm{Cr}, \mathrm{Fe}, \mathrm{W}, \mathrm{V}$ a C.

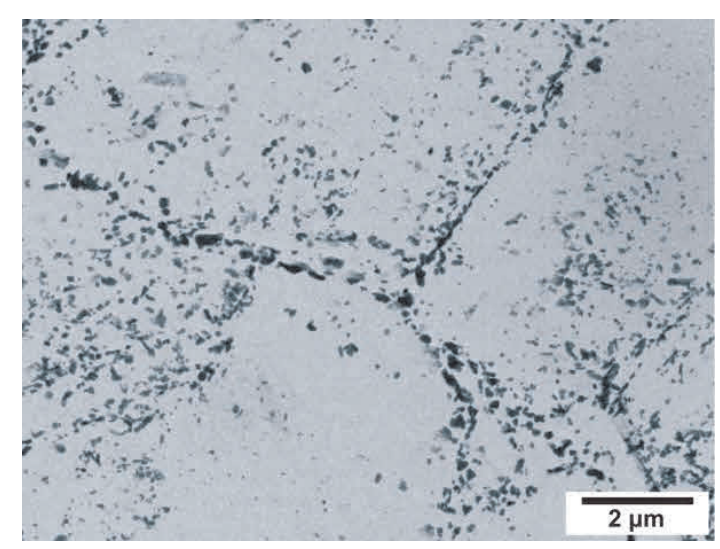

Figure 7 substructure and distribution particles at the original austenite grain boundaries

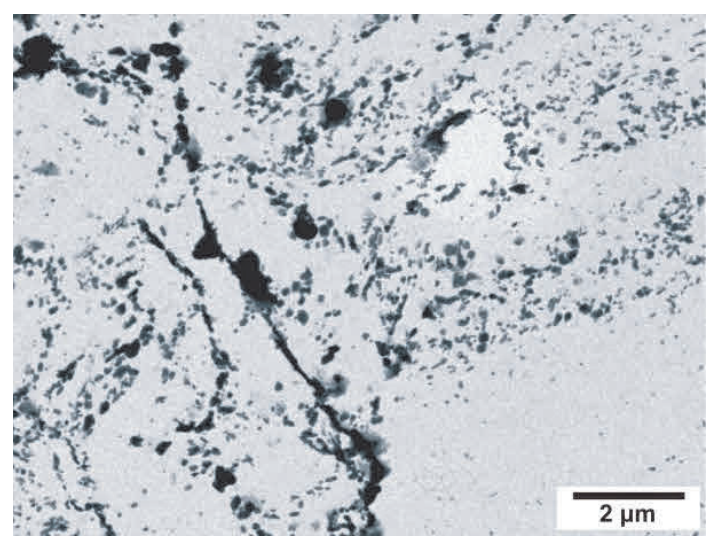

Figure 8 substructure and distribution particles, at the original austenite grain boundaries

From the analysed states (N1, N3, S1 and S3), were evaluated mechanical properties. Our 9CrNB steel is not listed in the standards, yet. The achieved mechanical properties are compared with the steel grade P92. The prescribed mechanical properties for grade P92 are described in Table 2. Table 3 shows the achieved mechanical properties after austenitization and subsequent tempering. The values of mechanical properties after austenitization have of minor importance, since the tubes of these grades must be delivered in normalizing and temepring conditions. The value of yield strength $R_{p 0.2}$, tensile strength $R_{m}$ and impact notch toughness KV, meet the prescribed properties with a large margin. Hardness HBW moves very closely around the max. value of 250 , even slightly above it. The Elongation $A_{5}$ values were not achieved at tempering temperatures $790^{\circ} \mathrm{C}$ and holding time $60 \mathrm{~min}$.

Table 2 Mechanical properties according to the standard STN EN $10216-2$ at $+20{ }^{\circ} \mathrm{C}$

\begin{tabular}{|c|c|c|c|c|c|}
\hline Steel grade & $\mathbf{R}_{\mathbf{p} 0.2}-\min (\mathrm{MPa})$ & $\mathbf{R}_{\mathbf{m}}(\mathbf{M P a})$ & $\mathbf{A}_{\min }(\%)$ & $\mathbf{K V}(\mathbf{J})$ & HBW max \\
\hline X10CrWMoVNb9-2 (P92) & 440 & $620-850$ & 19 & 27 & 250 \\
\hline
\end{tabular}

Table 3 Achieved mechanical properties of analysed states

\begin{tabular}{|c|c|c|c|c|c|}
\hline States & $\mathbf{R}_{\mathrm{p} 0.2}(\mathrm{MPa})$ & $\mathbf{R}_{\mathrm{m}}([\mathrm{MPa})$ & $A_{5}(\%)$ & $\mathrm{KV}(\mathrm{J})$ & HBW \\
\hline $\mathrm{N} 1-1050{ }^{\circ} \mathrm{C} \_15 \mathrm{~min}$ & 964 & 1287 & 12.2 & 11.0 & 362 \\
\hline $\mathrm{N} 3-1050{ }^{\circ} \mathrm{C} \_45 \mathrm{~min}$ & 941 & 1237 & 11.9 & 10.3 & 371 \\
\hline $\begin{array}{l}\mathrm{S} 1-1050^{\circ} \mathrm{C} \_15 \mathrm{~min} \\
\text { TEMP. } 790^{\circ} \mathrm{C} \_60 \mathrm{~min}\end{array}$ & 614 & 739 & 16.9 & 203.0 & 251 \\
\hline $\begin{array}{l}\mathrm{S} 3-1050^{\circ} \mathrm{C} \_45 \mathrm{~min} \\
\text { TEMP. } 790^{\circ} \mathrm{C} \_60 \mathrm{~min}\end{array}$ & 620 & 746 & 16.5 & 107.0 & 248 \\
\hline
\end{tabular}

\section{DISCUSSION}

Microstructure and substructure after austenitization (state N1 and N3) consists of martensite lath and low bainite lath. In substructure oval particles with an average size of $200 \mathrm{~nm}$ and also irregular particles with 
uneven distribution with an average size of $800 \mathrm{~nm}$ were present in some areas. To a large extent, irregular larger particles were bound to the original austenite grain boundaries. They were also within the martensite and bainite laths as well as smaller sized particles. At state S1 and S3 microstructure consists of temepered martensite and tempered lower bainite. Globular to oval particles reached an average size $60 \mathrm{~nm}$. These particles are identified as $\mathrm{Nb}, \mathrm{V}, \mathrm{C}$ or $\mathrm{Nb}, \mathrm{V}, \mathrm{B}, \mathrm{C}$, based on results of EDX analysis. Particles on base $\mathrm{Nb}, \mathrm{V}$ and $\mathrm{C}$ were identified by electron diffraction analysis as niobium carbides with possible vanadium atom substitution in the crystallographic cubic $\mathrm{NbC}$ centered lattice (state $\mathrm{S} 1$ and $\mathrm{S} 3$ ). Particles on base $\mathrm{Nb}, \mathrm{V}, \mathrm{B}$ a $\mathrm{C}$ were identified as niobium carbides alloyed with boron with possible vanadium atom substitution in the crystallographic cubic $\mathrm{NbC}$ centered (state $\mathrm{S} 1$ ) and niobium boride with possible substitution of vanadium atoms in the crystallographic orthorhombic lattice of $\mathrm{NbB}$ phase (state S3). The role of these fine particles of $\mathrm{M}(\mathrm{C}, \mathrm{N})$ type precipitates, in which $\mathrm{M}$ can be $\mathrm{Nb}$ or $\mathrm{V}$ is to stabilize the morphology of the tempered martensitic matrix and its dislocation substructure and thus contributing to the creep resistance of the steel [8,9]. Larger oval to rod-shaped particles reached a length of $200 \mathrm{~nm}$ and a width of $50 \mathrm{~nm}$. EDX analysis showed that they were based on $\mathrm{Cr}, \mathrm{Fe}, \mathrm{W}$ and $\mathrm{C}$. The particles were identified by selection electron diffraction analysis as complex $\mathrm{M}_{23} \mathrm{C}_{6}$ type carbides crystallizing in a crystallographic cubic surface centered lattice with possible substitution of chromium, iron and tungsten atoms. EDX analysis showed, that coarse oval to irregular particles present at the original austenitic grain boundaries of size $350 \mathrm{~nm}$ (state S1) up to $700 \mathrm{~nm}$ (state S3) were based on $\mathrm{Cr}$, Fe, W, V a C. 9CrNB steel has an increased W content compared to P92, which increases creep resistance through solution hardening and refining of the martensitic substructure. Cobalt stabilizes austenite, suppresses delta ferrite formation, and coarser $\mathrm{M}_{23} \mathrm{C}_{6}$ carbide particles. The addition of boron in optimal combination with nitrogen significantly increases the creep resistance of this steel as it reduces the rate of coarse $\mathrm{M}_{23} \mathrm{C}_{6}$ at high temperatures $[6,10]$. From the evaluation of the mechanical properties showed that the minimum requirements for the elongation (19\%) $A_{5}$ and requirements for hardness HBW at the max. value of

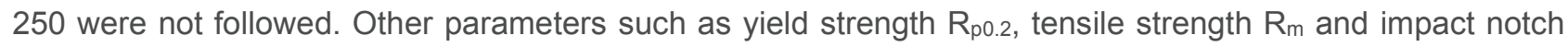
toughness KV meet the prescribed values with a large margin. The probable cause of high hardness and lower elongation was insufficient holding time on temepring temperature, which was $60 \mathrm{~min}$. Based on our experience in operating conditions, the optimum holding time at tempering temperature is about $240 \mathrm{~min}$. At longer holding time, the values of strength and hardness would be reduced. At the same time, the elongation $A_{5}$ would increase.

\section{CONCLUSION}

1) Microstructure after austenitization (state N1 and N3) consists of martensite lath and low bainite lath. At state $\mathrm{S} 1$ and $\mathrm{S} 3$ microstructure consists of temepered martensite and tempered lower bainite.

2) The particles have a rod-shaped character inside the martensite and bainite and has different orientation in different regions of the substructure and reached an average length of $130 \mathrm{~nm}$. Inside the martensite and bainite and their interfaces are also visible smaller globular and oval particles with an average size $50 \mathrm{~nm}$.

3) Globular to oval particles reached an average size $60 \mathrm{~nm}$ (in states $\mathrm{S} 1$ and S3). These particles are identified as $\mathrm{Nb}, \mathrm{V}, \mathrm{C}$ or $\mathrm{Nb}, \mathrm{V}, \mathrm{B}, \mathrm{C}$, based on results of EDX analysis. Particles on base $\mathrm{Nb}, \mathrm{V}$ and $\mathrm{C}$ were identified by selecton electron diffraction analysis as niobium carbides with possible vanadium atom substitusion in the crystallographic cubic NbC centered lattice (state S1 and S3). Particles on base $\mathrm{Nb}, \mathrm{V}, \mathrm{B}$ a C were identified as niobium carbides alloyed with boron with possible vanadium atom substitution in the crystallographic cubic $\mathrm{NbC}$ centered (state $\mathrm{S} 1$ ) and niobium boride with possible substitution of vanadium atoms in the crystallographic orthorhombic lattice of NbB phase (state S3).

4) Larger oval to rod-shaped particles reached a length of $200 \mathrm{~nm}$ and a width of $50 \mathrm{~nm}$. EDX analysis showed that they were based on $\mathrm{Cr}, \mathrm{Fe}, \mathrm{W}$ and $\mathrm{C}$. The particles were identified by selection electron diffraction analysis as complex $\mathrm{M}_{23} \mathrm{C}_{6}$ type carbides crystallizing in a crystallographic cubic surface centered lattice with possible substitution of chromium, iron and tungsten atoms. EDX analysis showed, that coarse oval to irregular particles present at the original austenitic grain boundaries of size $350 \mathrm{~nm}$ (state S1) up to $700 \mathrm{~nm}$ (state S3) were based on Cr, Fe, W, V a C. 
5) From the evaluation of the mechanical properties showed that the minimum requirements for the elongation (19\%) $A_{5}$ and requirements for hardness HBW at the max. value of 250 were not followed.

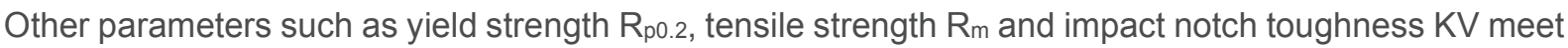
the prescribed values with a large margin. The probable cause of high hardness and lower elongation was insufficient holding time on temepring temperature, which was $60 \mathrm{~min}$. To meet all mechanical properties. To achieve all the standards required mechanical properties will need to deal with the extension of time tempering.

\section{ACKNOWLEDGEMENTS}

This work was supported by the project APVV-15-0723 (CREEPWELD) - Welding technology development for unique creep resistant steels currenly developed in Železiarne Podbrezová, a.s.

\section{REFERENCES}

[1] DUDOVA, N., MISHNEV, R. and KAIBYSHEY, R. Effect of Tempering on Microstructure and Mechanical Properties of Boron Containing 10 \% Cr Steel. ISIJ International. 2011. vol. 51, no. 11, pp. 1912-1918.

[2] SAWADA, K., TANEIKE, M., KIMURA, K. and ABE, F. Effect of Nitrogen Content on Microstructural Aspects and Creep Behavior in Extremely Low Carbon 9Cr Heat-resistant Steel. ISIJ International. 2004. vol. 44, no. 7, pp. 1243-1249.

[3] GUSTAFSON, Å. And ÅGREN, J. Possible Effect of Co on Coarsening of $\mathrm{M}_{23} \mathrm{C}_{6}$ Carbide and Orowan Stress in a $9 \%$ Cr Steel. ISIJ International. 2001. vol. 41, pp. 356-360.

[4] OKADA, H., MUNEKI, S., YAMADA, K., OKUBO, H., IGARASHI, M. and ABE. F. Effects of Alloying Elements on Creep Properties of 9Cr-3.3W-0.5Pd-V, Nb, N, B Steel. ISIJ International. 2002, vol. 42, no. 10, pp. 169-1174.

[5] PARILÁK, L', BEKEČ, P. and BERAXA, P. Influence of Austenitizing Temperature on Microstructure and Kinetics Growth of Austenite Grain in 9 CrNB Steel. In: Metal 2017: 26th International Conference on Metallurgy and Materials. Ostrava: TANGER Ltd, 2017, pp. 968-972.

[6] ABE, F. Research and Development of Heat-Resistant Materials for Advanced USC Power Plants with Steam Temperatures of $700{ }^{\circ} \mathrm{C}$ and Above. Engineering. 2015. vol.1, no. 2, pp. 211-224.

[7] KAYBYSHEV, R.O., SKOROBOGATYKH, V.N. and SHCHENKOVA, I.A. New martensitic steels for fossil power plant: Creep resistance. Physics of Metals and Metallography. 2010. vol.109, no. 2, pp. 186-200.

[8] ABE, F. Precipitate design for creep strengthening of $9 \% \mathrm{Cr}$ tempered martensitic steel for ultra-supercritical power plants. Science and Technology of Advanced Materials. 2008. vol. 9, no. 1, 15 p.

[9] ABE, F., TABUCHI, M., SEMBA, H., IGARASHI, M., YOSHIZAWA, M., KOMAI, N. and FUJITA, A. Feasibility of MARBN Steel for Application to Thick Section Boiler Components in USC Power Plant at $650{ }^{\circ} \mathrm{C}$. In: Advances in Materials Technology for Fossil Power Plants: 5th International Conference. R. Viswanathan, D. Gandy, K. Coleman, 2008, pp. 92-106.

[10] MARUYAMA, K., SAWADA, K., KOIKE, J. Strengthening Mechanisms of Creep Resistant Tempered Martensitic Steel. ISIJ International. 2001. vol.41, no. 6, pp. 641-653. 